See discussions, stats, and author profiles for this publication at: https://www.researchgate.net/publication/321142030

\title{
Development of A Questionnaire To Assess People's Food Choices Determinants
}

Article in Current Nutrition \& Food Science · November 2017

DOI: $10.2174 / 1573401313666171117150648$

CITATIONS

6 authors, including:

Raquel Pinho Ferreira Guiné

Polytechnic Institute of Viseu

471 PUBLICATIONS 1,839 CITATIONS

SEE PROFILE

Manuela Ferreira

91 PUBLICATIONS 155 CITATIONS

SEE PROFILE

Some of the authors of this publication are also working on these related projects:

Bridges between family and organic farming View project

Study about the knowledge and habits regarding food fibres in different countries View project
589

Paula Correia

Polytechnic Institute of Viseu

20 PUBLICATIONS 20 CITATIONS

SEE PROFILE

Joao Duarte

Instituto Superior de Contabilidade e Administração de Coimbra 111 PUBLICATIONS 161 CITATIONS

SEE PROFILE 
Published article / Citation:

Ferrão AC, Guiné RPF, Correia P, Ferreira M, Duarte J, Lima J (2019) Development of a Questionnaire to Assess People's Food Choices Determinants. Current Nutrition and Food Sciene, 15(3), 281-295.

\title{
Author version
}

\section{DEVELOPMENT OF A QUESTIONNAIRE TO ASSESS PEOPLE'S FOOD CHOICES DETERMINANTS}

\author{
Ana Cristina Ferrão ${ }^{1 *}$, Raquel P. F. Guiné ${ }^{1,2}$, Paula Correia ${ }^{1}$, Manuela Ferreira ${ }^{1}$, João Duarte ${ }^{1}$ \\ João Lima ${ }^{3}$
}

${ }^{1}$ CI\&DETS Research Centre, Polytechnic Institute of Viseu, Campus Politécnico, Repesees, Viseu, Portugal. ${ }^{2}$ CITAB Research Centre, University of Trás-os-Montes, Vila Real, Portugal.

${ }^{3}$ Faculdade de Ciências da Nutrição e Alimentação da Universidade do Porto.

Address correspondence to:

Prof. Raquel Guiné (raquelguine@ esav.ipv.pt) 


\begin{abstract}
BACKGROUND: Diet and nutrition are major determinants of public health and are associated with a large number of diseases. Therefore, in order to plan actions to promote global health it is crucial to understand people's food choices.

OBJECTIVE: The aim of this study was the development and validation of a new instrument, a questionnaire to measure psycho-social motivations associated with food choices and eating practices.

METHODS: A descriptive cross-sectional study was undertaken on a non-probabilistic sample of 382 adult participants. The questionnaires were applied after informed consent only to adults (aged 18 or over) and the data were collected from January to April 2017 among the Portuguese population. The analysis has been conducted to explore the item-item correlation and the reliability of this new instrument.

RESULTS: The results indicated satisfactory correlations between the items of the different variables, except for Variable D (Social and cultural motivations) that did not show strong and significant correlations for almost any items. Considering all the items in each of the variables studied, Cronbach's alpha values ranged from 0.32 for the marketing and commercial motivations to 0.64 for the economical and availability motivations. When some items were removed from the variables, the values of Cronbach's alpha increased and ranged from 0.66 for social and cultural motivations to 0.78 for health, environmental and political motivations, and for marketing and commercial motivations.
\end{abstract}

CONCLUSION: This work suggested that this questionnaire could be considered a suitable tool for exploring food choice determinants.

Keywords: Diet, eating, food choices, health, motivations, nutrition, questionnaire, validation 


\section{INTRODUCTION}

The various functions of life are completely dependent on the energy we obtain through the metabolization of the food we eat. The main factors for eating are hunger and satiety, however what we choose to eat is not determined exclusively by physiological or nutritional needs [1]. In addition to the main factors that prompt us to eat, there are a wide range of other factors affecting our food choices, such as, health motivations; economic factors; emotional aspects; cultural influences; marketing and commercial and environmental concerns [2-7].

Food choices can have many consequences and a diet that contains adequate amounts of certain types of food can help to reduce the risk of developing several non-communicable diseases, such as obesity, diabetes, cardiovascular disease and cancer [8]. Despite the health benefits associated with a healthy diet, still unhealthy food choices, overweight and obesity contribute to a number of chronic diseases and are among the leading risk factors for death and disability worldwide [9-11]. Therefore, given the priority for population dietary change and in order to plan strategies that can improve dietary health and wellbeing, it is essential not only to understand food choice incentives, but also to understand variations in food choice determinants across different countries and cultures $[12,13]$.

There are a several measures to assess motives for eating behavior, focusing on different aspects. Some of them focus on the reasons for eating and others on food choices in everyday life [2]. For example, the Motivations to Eat Scale measures the psychological motivations to eat based on a fourcategory model (to cope with negative affect, to be social, to comply with others' expectations, and to enhance pleasure) [14]; the Dutch Eating Behavior Questionnaire (DEBQ) assesses restrained, emotional, and external eating behavior [15]; the Health and Taste Attitudes Questionnaire assesses consumers' orientations toward the health and hedonic characteristics of foods [16]; the Eating Motivation Survey (TEMS) allows a characterization of the motives associated with food choice [2]; the Food Choice Questionnaire (FCQ) encompasses nine different food choice motives for everyday life (health, mood, convenience, sensory appeal, natural content, price, weight control, familiarity and ethical concern) [4]; the Measurement of Ethical Food Choice Motives added three new items to the FCQ about Ecological Welfare, Political Values and Religion [17].

This project entitled "Psycho-social motivations associated with food choices and eating practices (EATMOT)" is a study about the different psychological and social motivations that determine people's eating patterns in relation to their choices or eating habits and the range of the study will be multinational. Therefore, we developed a questionnaire aimed specifically for this project. The questionnaire compiled different perspectives provided by existing research about the 
motivations on eating behavior, but also extended them by including others motives identified by the project team members.

The objective of this paper is to describe the internal validation of the questionnaire, in terms of semantics and internal structure, for the Portuguese population, so that it could then be used by the participants in other countries in a later phase of the project.

\section{MATERIALS AND METHODS}

\subsection{Instrument}

For this study a questionnaire was developed to evaluate the psycho-social motivations associated with food choices and eating practices. Motivations influencing the eating behaviour were compiled through a review of previous publications and discussed between the team members. Some of the motives were adapted from FCQ [4], DEBQ [15], Motivations to eat scale [14], Measurement of ethical food choice motives [17], Eating Motivation Survey (TEMS) [2], Health and Taste Attitudes Questionnaire [16], and Informational Bases of Food Questionnaire [18].

The first draft of the questionnaire was prepared in English by the six Portuguese team members and sent to all partners of this project, in a total of 64 researchers from 17 different countries (Argentina, Brazil, Croatia, Cyprus, Egypt, Greece, Hungary, Italy, Latvia, Lithuania, Macedonia, Netherlands, Poland, Romania, Serbia, Slovenia and United States of America). After gathering all contributions, the Portuguese team prepared the working version of the questionnaire and translated it from English to Portuguese. The working version of the questionnaire in Portuguese was sent to a group of professionals of different areas for semantic validation (Food Science -3 , Nutrition -4 , Health Sciences - 1, Education sciences and Psychology - 1). The working version was submitted to a pre-test, which included application to 50 persons selected randomly among the Portuguese population. After that, the questionnaire was altered according to possible misunderstandings and other suggested changes. Finally, the questionnaire was applied to a sample of at least 200 people to undertake statistical validation [19].

In total, 65 reasons to eat and choose certain food items were compiled according to the different sources. Table 1 shows the number of items corresponding to the different motivations for food choices. 
Table 1. Number of items regarding the attitudes and motivations for food choices.

\begin{tabular}{l|c|c}
\hline Variable & Motivations & No of Items \\
\hline HM & Healthy motivations & 11 \\
\hline EM & Emotional motivations & 10 \\
\hline EAM & Economic and availability motivations & 8 \\
\hline SCM & Social and cultural motivations & 11 \\
\hline EPM & Environmental and political motivations & 8 \\
\hline MCM & Marketing and commercial motivations & 7 \\
\hline
\end{tabular}

The questionnaire included different sections, destined to collect information about several important issues: Part I - Sociodemographical data; Part II - Anthropometric data and behavioural and health related elements; Part III - Attitudes relating to healthy food; Part IV - Sources of information about a healthy diet; Part V - Healthy motivations; Part VI - Emotional motivations; Part VII - Economic and availability motivations; Part VIII - Social and cultural motivations; Part IX - Environmental and political motivations; Part X - Marketing and commercial motivations. In order to assess the participants opinions, they were asked to state their accordance measured on a 5point Likert scale varying from 1 (totally disagree) to 5 (totally agree) [20].

\subsection{Data collection}

A descriptive cross-sectional study was performed on a non-probabilistic sample with 382 participants living in Portugal. The questionnaires were applied after informed consent only to adults (aged 18 or over). All ethical issues were verified when formulating and applying the questionnaire, which was approved by the Ethical Committee with reference $n^{\circ} 04 / 2017$.

\subsubsection{Pre-test}

The objective of this phase was to determine if the questions were perceptible and if they had the qualities inherent to the measurement [19].

For the pre-test, the questionnaires were applied by direct interview to a restricted sample of 50 participants, which is the number indicated by Hill and Hill [19] for this type of assessment. The data were collected from January to February of 2017 among the Portuguese population.

This pre-test allowed identifying some questions that eventually were not very clear for the participants, and therefore they were rewritten and/or reformulated accordingly. 


\subsubsection{Validation test}

For the validation test, the questionnaire, changed according to the results of the pre-test, was applied to a sample of 332 participants, which was higher than the minimum number of participants required for validation advised by Hill and Hill [19], and which is 100. The data were collected from March to April of 2017 among the Portuguese population.

\subsection{Statistical analysis}

Basic descriptive statistical tools were used for exploratory analysis of the data.

In order to perform item analysis the Inter-Item Correlations and Item-Total Correlations were calculated. Item analysis is applicable to samples over 100 participants, and therefore is valid for the present case. Item analysis was made through the Pearson correlation coefficients, which measures the association between two variables according to the magnitude of the absolute value [29-31]. If $0.00<\mathrm{r}<0.10$ the association is very weak, if $0.10 \leq \mathrm{r}<0.30$ the association is weak, if $0.30 \leq \mathrm{r}<$ 0.50 the association is moderate, if $0.50 \leq \mathrm{r}<0.70$ the association is strong and if $0.70 \leq \mathrm{r}<1.00$ the association is very strong. For $r=0$ there in no association and for $r=1$ the association is perfect.

The reliability of the scales was evaluated through the calculation of the Cronbach's alpha $(\alpha)$, which measures the internal consistency of the scale for the different statements evaluated [21] in each of the variables (groups of items of the same type). Cronbach's alpha $(\alpha)$ values range from 0.0 to 1.0. Higher scores indicate a more reliable, homogenous scale in which the individual items in each domain of the questionnaire reliably measure the domain core concept [22]. According to Hill and Hill [19], alpha can be interpreted as follows: $\alpha<0.6$ - unacceptable internal reliability; $0.60 \leq \alpha$ $<0.70$ - weak internal reliability, $0.70 \leq \alpha<0.80$ - acceptable internal reliability, $0.80 \leq \alpha<0.90$ good internal reliability and $\alpha \geq 0.90$ - excellent internal reliability.

The analysis of the data was made by using SPSS software from IBM Inc. (version 24).

\section{RESULTS AND DISCUSSION}

\subsection{Sample characterization}

Table 2 summarizes the demographical data for the sample studied. This study involved 382 participants aged between 18 and 70 years, aged on average $26 \pm 11$ years, being $77 \%$ women and $33 \%$ men. The average age of men, $28 \pm 13$ years, was higher when compared to women, $25 \pm 10$ years. As for age, the participants were classified into categories: young adults $(18 \leq$ age $\leq 30)$, corresponding to $82.2 \%$; average adults $(31 \leq$ age $\leq 50)$, accounting for $13.1 \%$; senior adults $(51 \leq$ age $\leq 64)$, representing $3.9 \%$; and finally elderly $(\geq 65)$, which accounted for $0.8 \%$ of the sample. 
According to the living environment, $46.3 \%$ of the participants indicated that they lived in an urban area, $40.8 \%$ in a rural environment and $12.3 \%$ in a suburban area.

Regarding the level of education, most of the participants, $79.6 \%$, had completed secondary school, $20.2 \%$ had a university degree and only $0.3 \%$ had the lowest level of education (primary school).

Concerning the civil state, $82.2 \%$ of the participants were single, $14.7 \%$ married or lived together as a marital couple, $2.6 \%$ separated or legally divorced and $0.5 \%$ widowers.

As for the profession, most of the participants, $74.3 \%$, were students, $17.5 \%$ were employed, $7.3 \%$ were working students, $0.5 \%$ were unemployed, and only $0.3 \%$ were retired.

Concerning the participants' professional activity or field of studies, it was observed that $36.3 \%$ of the participants did not have any professional activity or field of studies related to any of the options suggested (nutrition, food science, agriculture, sport, psychology, activities related to health), $30.2 \%$ had a professional activity or field of studies related to health, $12.4 \%$ had a professional activity or field of studies related to sport and only $0.8 \%$ had an activity or studies in the nutrition area. Furthermore, $43.5 \%$ of the men indicated that they had an activity or studies in sport area and $40.1 \%$ of the women had activities/studies in different areas from those suggested. The results also showed that a higher percentage of the women, $34.8 \%$, had a professional activity or studies related to health when compared to men $(15.3 \%)$. 
Table 2. Sociodemographical characterization.

Sociodemographic Data

Frequency Percentage

\begin{tabular}{|c|c|c|c|}
\hline & & $(\mathbf{N})$ & $(\%)$ \\
\hline \multirow[t]{4}{*}{ Age } & $18 \leq$ age $\leq 30$ & 314 & 82.2 \\
\hline & $31 \leq$ age $\leq 50$ & 50 & 13.1 \\
\hline & $51 \leq$ age $\leq 64$ & 15 & 3.9 \\
\hline & Age $\geq 65$ & 3 & 0.8 \\
\hline \multirow[t]{2}{*}{ Gender } & Female & 294 & 77.0 \\
\hline & Male & 88 & 23.0 \\
\hline \multirow[t]{3}{*}{ Highest Level of Education } & Primary School & 1 & 0.3 \\
\hline & Secondary School & 304 & 79.6 \\
\hline & University Degree & 77 & 20.2 \\
\hline \multirow[t]{4}{*}{ Civil State } & Single & 314 & 82.2 \\
\hline & Married/Living Together & 56 & 14.7 \\
\hline & Divorced/Separated & 10 & 2.6 \\
\hline & Widow & 2 & 2.6 \\
\hline \multirow[t]{5}{*}{ Profession } & Student & 284 & 74.3 \\
\hline & Employed & 67 & 17.5 \\
\hline & Unemployed & 2 & 0.5 \\
\hline & Retired & 1 & 0.3 \\
\hline & Working student & 28 & 7.3 \\
\hline \multirow[t]{7}{*}{ Profession } & Nutrition & 3 & 0.8 \\
\hline & Food & 42 & 11.5 \\
\hline & Agriculture & 16 & 4.4 \\
\hline & Sport & 45 & 12.4 \\
\hline & Psychology & 16 & 4.4 \\
\hline & Health & 11.0 & 30.2 \\
\hline & Others & 132 & 36.3 \\
\hline \multicolumn{2}{|c|}{ Total Number of Participants } & 382 & 100.0 \\
\hline
\end{tabular}


When the participants were asked if they were responsible for buying their own food, $83.1 \%$ answered yes against $16.9 \%$ that answered no, being this percentage higher for women $(85.2 \%)$ than for men $(76.1 \%)$.

\subsection{Internal structure validation}

3.2.1. Item-item analysis

\subsubsection{Healthy motivations}

Nowadays, food choices are under greater public scrutiny due to concerns of over-nutrition and an unhealthy diet has been implicated in increasing levels of obesity and chronic diseases. Hence, what to eat, when to eat and in what quantities has become an integral part of social and medical discourse [23]. Thus, being the main purpose of this survey to understand the motivations affecting food choices, the healthy motivations were investigated.

Table 3 shows the item-item correlations for Variable HM (Healthy Motivations). The results obtained showed that the strongest correlation was between item 8 , related to the importance of the consumption of healthy foods, and item 4 associated to the consumption of vitamins and minerals, with a value equal to 0.57 (statistically significant correlation). Next, also with a statistically significant correlation, appeared the correlation between items 11 (diet low in sugar) and 2 (diet low in fat), with a value equal to 0.51 and the correlation between items 9 (consumption of foods that may raise blood sugar - glycaemia) and 5 (consumption of foods that may raise cholesterol), also with a value of 0.51 . 
Table 3. Item-item correlations for Variable HM (Healthy Motivations).

\begin{tabular}{|c|c|c|c|c|c|c|c|c|c|c|c|}
\hline Items $^{1}$ & 1 & 2 & 3 & 4 & 5 & 6 & 7 & 8 & 9 & 10 & 11 \\
\hline 1 & 1 & & & & & & & & & & \\
\hline 2 & $0.27^{* *}$ & 1 & & & & & & & & & \\
\hline 3 & $0.25^{* * *}$ & $0.32^{* *}$ & 1 & & & & & & & & \\
\hline 4 & $0.36^{* *}$ & $0.36^{* *}$ & $0.44^{* *}$ & 1 & & & & & & & \\
\hline 5 & $-0.11^{*}$ & $-0.37^{* *}$ & $-0.31^{* *}$ & $-0.32^{* *}$ & 1 & & & & & & \\
\hline 6 & $0.26^{* *}$ & $0.29^{* * *}$ & $0.30^{* *}$ & $0.35^{* *}$ & $-0.30^{* *}$ & 1 & & & & & \\
\hline 7 & $0.19^{* *}$ & $0.24^{* *}$ & $0.19^{* *}$ & $0.15^{* *}$ & $-0.15^{* *}$ & $0.37^{* *}$ & 1 & & & & \\
\hline 8 & $0.30^{* *}$ & $0.41^{* *}$ & $0.40^{* *}$ & $0.57^{* *}$ & $-0.35^{* *}$ & $0.40^{* * *}$ & $0.17^{* *}$ & 1 & & & \\
\hline 9 & $-0.17^{* *}$ & $-0.20^{* *}$ & $-0.23^{* *}$ & $-0.23^{* *}$ & $0.51^{* * *}$ & $-0.37^{* *}$ & $-0.23^{* *}$ & $-0.27^{* *}$ & 1 & & \\
\hline 10 & $0.11^{*}$ & $0.11^{*}$ & $0.11^{*}$ & 0.09 & -0.09 & $0.32^{* *}$ & $0.34^{* *}$ & $0.23^{* *}$ & -0.09 & 1 & \\
\hline 11 & $0.27^{* *}$ & $0.51^{* *}$ & $0.41^{* *}$ & $0.40^{* *}$ & $-0.43^{* *}$ & $0.44^{* *}$ & $0.29^{* *}$ & $0.44^{* *}$ & $-0.34^{* *}$ & $0.21^{* *}$ & 1 \\
\hline
\end{tabular}

1 Item legend: $1=$ Hygiene, $2=$ Low fat, $3=$ Healthy and balanced diet, $4=$ Vitamins and minerals, $5=$ Cholesterol, $6=$ Additives, $7=$ Processed foods, $8=$ Healthy foods, $9=$ Glycaemia, $10=$ Genetically modified foods, 11 = Low sugar.

** Correlation is significant at the 0.01 level.

* Correlation is significant at the 0.05 level.

The item that showed a better correlation with a greater number of items was the 11 , being this associated to the importance of a diet low in sugar. This item showed a strong correlation with item 2 (0.51), and moderate correlations with items $6(0.44), 8(0.44), 3(0.41)$ and $4(0.40)$. Regarding item 5 , the correlation was negative, because it corresponds to a question made in a negative way, as it can be observed in Annex A. The results are consistent with the concept of a healthy eating, which is associated to the consumption of vegetables, fruits, whole grains, low-fat dairy products and less refined grain, saturated fatty acids, and added sugars [24,25].

On the other hand, the item that had the worst correlation with almost all other items was number 10, associated to the consumption of genetically modified foods (GM foods). GM foods are still a controversial subject, due to lack of knowledge, misconceptions and even a lack of familiarity with GM food products by worldwide consumers [26].

\subsubsection{Emotional motivations}

Emotions have a uniquely important role in food consumption and specific emotions such as anger, fear, sadness, and joy, as well as moods have been found to affect eating responses along the entire process of ingestion [27,28].

Table 4 presents the item-item correlations for Variable EM (Emotional Motivations) and as it can be observed the strongest correlation was between item 6 ("When I feel lonely, I console myself 
by eating") and item 1 ("Food helps me cope with stress"), with a score of 0.62 and a statistically significant correlation. Regarding item 1, it also presented a strong and positive correlation with item 10 ("I have more cravings for sweets when I am depressed"), moderate and positive correlations with items 5 ("Food makes me feel good") and 7 ("I eat more when I have nothing to do"), and a strong and negative correlation with item 9 ("For me, food does not serve as an emotional consolation"). The results also revealed a strong and positive correlation between items 10 and 6, with a score of 0.54 (statistically significant correlation). According to the evidences, stress may affect eating behavior by changing food intake patterns and food choices [29,30]. In fact, "stress-related eating," “eating comfort foods," and "emotional eating," are direct consequences of negative mood states, such as sadness, loneliness, and concern [31,32,32,33].

Table 4. Item-item correlations for Variable EM (Emotional Motivations).

\begin{tabular}{|c|c|c|c|c|c|c|c|c|c|c|}
\hline Items $^{1}$ & 1 & 2 & 3 & 4 & 5 & 6 & 7 & 8 & 9 & 10 \\
\hline 1 & 1 & & & & & & & & & \\
\hline 2 & -0.02 & 1 & & & & & & & & \\
\hline 3 & 0.17 & -0.07 & 1 & & & & & & & \\
\hline 4 & $0.12^{*}$ & $0.19^{* *}$ & $0.14^{* *}$ & 1 & & & & & & \\
\hline 5 & $0.49^{* *}$ & -0.05 & $0.13^{*}$ & -0.01 & 1 & & & & & \\
\hline 6 & $0.62^{* *}$ & $-0.14^{* * *}$ & $0.23^{* *}$ & $0.10^{* *}$ & $0.39^{* * *}$ & 1 & & & & \\
\hline 7 & $0.31^{* *}$ & $-0.19^{* * *}$ & $-0.19^{* *}$ & -0.01 & $-0.36^{* *}$ & $0.48^{* *}$ & 1 & & & \\
\hline 8 & 0.08 & $0.24^{* *}$ & 0.06 & $0.18^{* *}$ & $0.13^{*}$ & $0.12^{*}$ & 0.08 & 1 & & \\
\hline 9 & $-0.60^{* *}$ & $0.14^{* *}$ & $-0.12^{*}$ & -0.02 & $-0.34^{* *}$ & $-0.56^{* *}$ & $-0.29^{* *}$ & -0.00 & 1 & \\
\hline 10 & $0.54^{* *}$ & $-0.11^{*}$ & $0.14^{* *}$ & $0.16^{* *}$ & $0.28^{* *}$ & $0.54^{* *}$ & $0.38^{* *}$ & 0.04 & $-0.49^{* * *}$ & 1 \\
\hline
\end{tabular}

As for the items 2 ("I usually eat food that helps me control my weight"), 3 ("I often consume foods that keep me awake and alert"), 4 ("I often consume foods that helps me relax") and 8 ("It is important for me to eat less than usual when I gain weight"), they showed very weak and weak correlations with all other items. These results are not consistent with previous research, where it was found a positive and strong correlation between mood and weight control [13].

Since item 9 corresponded to a question made in the negative, as it was expected, it revealed a negative correlation with all items, except for item 2. 


\subsubsection{Economical and availability motivations}

Cost of food plays and important role in food choices. Whether cost is prohibitive or not, depends fundamentally on a person's income and socio-economic status. Accessibility to shops or food availability are other important physical factors influencing food choice, which are dependent on resources such as transport and geographical location [12].

Table 5 refers to the item-item correlation for Variable EAM (Economical and Availability Motivations). In first place figured the strong correlation between items 4 (easy to find) and 3 (preference for low price food), with a value of 0.51 and a statistically significant correlation, followed by the strong association between items 8 (purchase of food that is ready to eat or precooked) and 6 (food that is easy to prepare), with a value of 0.50 and a statistically significant correlation. Item 8 also showed a moderate and statistically significant correlation with item 7 ("I usually buy food that it is on sale").

Table 5. Item-item correlations for Variable C (Economical and Availability Motivations).

\begin{tabular}{|c|c|c|c|c|c|c|c|c|}
\hline Items $^{1}$ & 1 & 2 & 3 & 4 & 5 & 6 & 7 & 8 \\
\hline 1 & 1 & & & & & & & \\
\hline 2 & $0.38^{* *}$ & 1 & & & & & & \\
\hline 3 & $0.13^{*}$ & $0.27^{* *}$ & 1 & & & & & \\
\hline 4 & $0.10^{*}$ & $0.33^{* *}$ & $0.51^{* *}$ & 1 & & & & \\
\hline 5 & $0.23^{* *}$ & 0.07 & $-0.14^{* *}$ & $-0.13^{*}$ & 1 & & & \\
\hline 6 & 0.04 & $0.15^{* *}$ & $0.25^{* *}$ & $0.33^{* *}$ & $-0.19^{* *}$ & 1 & & \\
\hline 7 & $0.16^{* *}$ & $0.30^{* *}$ & $0.38^{* *}$ & $0.28^{* *}$ & -0.05 & $0.32^{* *}$ & 1 & \\
\hline 8 & -0.09 & $0.12^{*}$ & $0.22^{* *}$ & $0.21^{\text {** }}$ & $-0.31^{* *}$ & $0.50^{* *}$ & $0.33^{* *}$ & 1 \\
\hline
\end{tabular}

1 Item legend: $1=$ Quality/Price ratio, $2=$ Convenience, $3=$ Low price, $4=$ Easy to find, $5=$ Fresh to cook, $6=$ Easy to prepare, $7=$ Sales, $8=$ Ready to eat.

** Correlation is significant at the 0.01 level.

* Correlation is significant at the 0.05 level.

It was also observed that items 2 (convenience) and 1 (quality/price ratio), as well as items 7 (purchase of food that it is on sale) and 3 (preference for low price food) had a moderate and positive correlation, with a value equal to 0.38 in both cases. These results are consistent with those obtained in other studies, in which were found strong and positive correlations between price and convenience $[2,13]$. Others moderate and positive associations were also found between items 4 and $2(r=0.33)$, items 6 and $4(\mathrm{r}=0.33)$, items 7 and $2(\mathrm{r}=0.3)$ and items 7 and $6(\mathrm{r}=0.32)$.In general, all the other items had correlations with values below 0.30 , meaning weak or very weak correlations. 


\subsubsection{Social and cultural motivations}

In the literature is well established that social context strongly influences eating behavior and some people tend to eat differently when they are with other people compared with when they eat alone [34]. On the other hand, cultural influences can also lead to differences in the habitual consumption of certain foods and in traditions of preparation [12]. However, in this study in most cases it was not found a strong correlation between the different items, as it can be seen in Table 6 (item-item correlations for Variable SCM (Social and Cultural Motivations). The exceptions were the moderate and significant correlations between items 4 ("I eat certain foods because other people (my colleagues, friends, family) also eat it") and 3 ("It is important to me that the food I eat is similar to the food I ate when I was a child"), with a value of 0.33 , between items 8 ("My diet is determined by my family tradition") and 3, equal to 0.31 , between 10 ("I usually eat food that is trendy") and 4, also with a value of 0.31 , and between items 10 and 7 ("I eat certain foods because I am expected to eat them"), with a value of 0.30 . In fact, people tend to adjust their eating behavior in order to manage their public image and create a certain impression on others [34], and parental influence in childhood seems to have long-term effects [35-37].

Table 6. Item-item correlations for Variable SCM (Social and Cultural Motivations).

\begin{tabular}{|c|c|c|c|c|c|c|c|c|c|c|c|}
\hline Items $^{1}$ & 1 & 2 & 3 & 4 & 5 & 6 & 7 & 8 & 9 & 10 & 11 \\
\hline 1 & 1 & & & & & & & & & & \\
\hline 2 & $0.25^{* *}$ & 1 & & & & & & & & & \\
\hline 3 & $0.12^{*}$ & $0.23^{* *}$ & 1 & & & & & & & & \\
\hline 4 & 0.05 & $0.25^{* *}$ & $0.33^{* *}$ & 1 & & & & & & & \\
\hline 5 & $-0.25^{* *}$ & -0.09 & 0.02 & 0.01 & 1 & & & & & & \\
\hline 6 & $0.17^{* *}$ & 0.09 & $0.15^{* *}$ & 0.09 & 0.01 & 1 & & & & & \\
\hline 7 & -0.01 & $0.16^{* *}$ & $0.16^{* *}$ & $0.23^{* *}$ & 0.09 & $0.27^{* * *}$ & 1 & & & & \\
\hline 8 & 0.10 & $0.20^{* *}$ & $0.31^{* *}$ & $0.25^{* *}$ & -0.10 & $0.29^{* *}$ & $0.26^{* *}$ & 1 & & & \\
\hline 9 & 0.00 & 0.05 & $-0.11^{*}$ & -0.07 & -0.03 & $0.12^{*}$ & 0.06 & $-0.11^{*}$ & 1 & & \\
\hline 10 & -0.02 & $0.12^{*}$ & $0.17^{* *}$ & $0.31^{* *}$ & 0.07 & $0.23^{* *}$ & $0.30^{* *}$ & $0.28^{* * *}$ & $0.17^{* *}$ & 1 & \\
\hline 11 & -0.04 & -0.03 & $0.15^{* *}$ & $0.10^{*}$ & 0.02 & -0.04 & $0.21^{* *}$ & $0.23^{* * *}$ & $-0.48^{* *}$ & 0.02 & 1 \\
\hline
\end{tabular}

1 Item legend: 1 = Pleasure, $2=$ Company, $3=$ Food from infant time, $4=$ Follow trends, $5=$ Eat alone, $6=$ Food from the season $7=$ Expectations, $8=$ Family tradition, $9=$ New foods, $10=$ Food trends, $11=$ Unknown foods.

** Correlation is significant at the 0.01 level.

* Correlation is significant at the 0.05 level.

The results also revealed a negative and statistically significant correlation between items 11 ("I am not comfortable to eat food that I am not accustomed to or that I do not know") and 9 ("I like to 
try new foods to which I am not accustomed"), with a score equal to -0.48 . The value was negative, because item 9 corresponds to a question made in a negative way. In the study developed by Markovina and her colleagues [13], it was found a moderate and positive correlation between familiarity and sensory appeal (0.49). Renner et al. [2] also found a strong and significant correlation between traditional eating and eating habits.

\subsubsection{Environmental and political motivations}

Some of the main problems that are associated with environmental concerns are the food consumption patterns [38]. Therefore, when consumers discuss food choices they consider the importance of the environment [17]. Political motives also have a strong influence in food choices [39].

As Table 7 shows the item-item correlations for Variable EPM (Environmental and Political Motivations) and the strongest correlation was between items 8 (associated to the minimal usage of packaging) and 7 (related to the restaurants waste policy), with a value equal to 0.53 . There were also found strong and positive correlations between items 6 (associated to human rights) and 5 (related to animal rights), 8 and 5 , moderate and positive correlations between items 8 and 1 (preparation/packaging of food in an environmental friendly way), 8 and 6, and finally, between items 5 and 1. As for the correlation between items 4 (chose of food from my own country) and 3 (indifference regarding the country of origin), it was negative (-0.46), because item number 3 was negatively associated with the variable measured.

Table 7. Item-item correlations for Variable EPM (Environmental and Political Motivations).

\begin{tabular}{|c|c|c|c|c|c|c|c|c|}
\hline Items $^{1}$ & 1 & 2 & 3 & 4 & 5 & 6 & 7 & 8 \\
\hline 1 & 1 & & & & & & & \\
\hline 2 & $0.35^{\text {** }}$ & 1 & & & & & & \\
\hline 3 & $-0.27^{* *}$ & -0.07 & 1 & & & & & \\
\hline 4 & $0.34^{* *}$ & $0.21^{* *}$ & $-0.46^{* *}$ & 1 & & & & \\
\hline 5 & $0.46^{* *}$ & $0.31^{* *}$ & $-0.26^{* * *}$ & $0.33^{* *}$ & 1 & & & \\
\hline 6 & $0.31^{\text {** }}$ & $0.15^{* *}$ & $-0.27^{* *}$ & $0.24^{* *}$ & $0.52^{* *}$ & 1 & & \\
\hline 7 & $0.29^{* *}$ & $0.16^{* *}$ & $-0.11^{*}$ & $0.16^{* *}$ & $0.35^{* *}$ & $0.36^{* *}$ & 1 & \\
\hline 8 & $0.48^{* *}$ & $0.25^{* *}$ & $-0.26^{* *}$ & $0.28^{* *}$ & $0.52^{* *}$ & $0.47^{* *}$ & $0.53^{* *}$ & 1 \\
\hline
\end{tabular}

1 Item legend: 1 = Environmental friendly, $2=$ Avoid waist, $3=$ Country of origin, $4=$ Food from my country, $5=$ Animal rights, $6=$ Human rights, $7=$ Restaurant waste policy, $8=$ Minimal packaging.

** Correlation is significant at the 0.01 level.

* Correlation is significant at the 0.05 level. 
The results also revealed moderate and significant correlations between other items, such as items 7 and 6 or items 2 (related to the importance of avoiding food waist) and 1. In last years, what was once a focus on environmental/'green' behavior has expanded to cover issues of animal welfare, human rights, country of origin, fair trade, health, anti-globalization and many other related concerns [40-42].

\subsubsection{Marketing and commercial motivations}

People are much influenced by what they see on social media, and commercials motivate people to choose some foods instead of others. Thus, marketing and packaging of foods also influences consumer dietary choices [43].

Table 8 presents item-item correlation for Variable MCM (Marketing and Commercial Motivations). In first place, with the highest value (0.61) and a significant correlation, came the correlation between items 5 (desire for advertised foods) and 2 (recognise from TV commercials), followed by the correlation between items 5 and 3 (appealing food), with a value equal to 0.53 and also a significant correlation. These results are consistent with the ones obtained in another study, where it was also found a strong and statistically significant correlation between the pleasure in the consumption and the visual appealing of foods (0.59) [2]. Despite technological innovations such as the internet, television is still the primary medium used for advertising food and drink products [44].

Table 8. Item-item correlations for Variable MCM (Marketing and Commercial Motivations).

\begin{tabular}{|c|c|c|c|c|c|c|c|}
\hline Items $^{1}$ & $\mathbf{1}$ & $\mathbf{2}$ & $\mathbf{3}$ & $\mathbf{4}$ & $\mathbf{5}$ & $\mathbf{6}$ & $\mathbf{7}$ \\
\hline $\mathbf{1}$ & 1 & & & & & & \\
\hline $\mathbf{2}$ & $-0.28^{* *}$ & 1 & & & & & \\
\hline $\mathbf{3}$ & $-0.26^{* *}$ & $-0.51^{* *}$ & 1 & & & & \\
\hline $\mathbf{4}$ & $0.29^{* *}$ & $-0.26^{* *}$ & $-0.29^{* *}$ & 1 & & & \\
\hline $\mathbf{5}$ & $-0.37^{* *}$ & $0.61^{* *}$ & $0.53^{* *}$ & $-0.33^{* *}$ & 1 & & \\
\hline $\mathbf{6}$ & -0.05 & $0.26^{* *}$ & 0.09 & 0.00 & $0.21^{* *}$ & 1 & \\
\hline $\mathbf{7}$ & -0.09 & $0.21^{* *}$ & 0.07 & $0.12^{*}$ & $0.14^{* *}$ & 0.09 & 1 \\
\hline
\end{tabular}

1 Item legend: $1=$ Advertising campaigns, $2=$ Recognise from TV commercials, $3=$ Appealing food, $4=$ Read labels, $5=$ Desire for advertised foods, $6=$ Brands, $7=$ Look for discounts.

** Correlation is significant at the 0.01 level.

* Correlation is significant at the 0.05 level.

It was further observed a negative but significant correlation between item 3 and 2, with a value equal to -0.51 . 


\subsubsection{Internal reliability}

\subsubsection{Healthy motivations}

The internal reliability for variable HM (Healthy Motivations) is shown in Table 9. First, it was analysed the internal reliability including all items, and it was observed that the value of Cronbach's alpha for Variable A was 0.56, which was weak. Therefore, the removal of items 5 and 9 increased alpha value to 0.79 , meaning an acceptable internal reliability. Moreover, the removal of item 10 practically did not increase alpha, and thus, it was concluded that item 10 should not be eliminated. In almost all of the previous studies, the healthy motivations and the natural content of foods were considered as two separate variables. So, when comparing the values obtained only with the health motivations of other studies, it was verified that Cronbach's alpha, after removing items 5 and 9, was similarly to the one obtained in those studies $(\alpha=0.87$ [4]; $\alpha=0.75,0.87,0.83$ [45]; $\alpha=0.72$ [46]; $\alpha=0.86[3])$.

In a study where it was applied the FCQ, considering healthy and natural content as one variable, it was obtained an alpha of 0.85 [47], being that value similar to the one obtained in the present study. 
Table 9. Internal reliability for Variable HM (Healthy Motivations).

\begin{tabular}{|l|c|c|c|}
\hline \multirow{2}{*}{ Items } & \multicolumn{3}{c}{ Cronbach's alpha if item deleted } \\
\cline { 2 - 4 } & $\begin{array}{c}\text { Considering } \\
\text { all items }\end{array}$ & $\begin{array}{c}\text { Removing item } \\
\text { 1 - Hygiene }\end{array}$ & $\begin{array}{c}\text { Removing } \\
\text { items 5 and 9 }\end{array}$ \\
\hline 2 - Low fat & 0.50 & 0.66 & 0.78 \\
\hline 3 - Healthy and balanced diet & 0.49 & 0.63 & 0.77 \\
\hline $\mathbf{4}$ - Vitamins and minerals & 0.48 & 0.64 & 0.77 \\
\hline $\mathbf{5}$ - Cholesterol & $\mathbf{0 . 6 9}$ & 0.63 & 0.77 \\
\hline 6 - Additives & 0.48 & --- & -- \\
\hline $\mathbf{7}$ - Processed foods & 0.50 & 0.63 & 0.76 \\
\hline $\mathbf{8}$ - Healthy foods & 0.48 & 0.66 & 0.78 \\
\hline 9 - Glycaemia & $\mathbf{0 . 6 6}$ & 0.63 & 0.76 \\
\hline $\mathbf{1 0}$ - Genetically modified foods & 0.52 & $\mathbf{0 . 7 9}$ & --- \\
\hline $\mathbf{1 1}$ - Low sugar & 0.47 & 0.67 & $\mathbf{0 . 8 0}$ \\
\hline No of items considered & $\mathbf{1 1}$ & 0.62 & 0.53 \\
\hline Cronbach's alpha & $\mathbf{0 . 5 6}$ & $\mathbf{1 0}$ & $\mathbf{0 . 6 9}$ \\
\hline Mean & $\mathbf{3 7 . 5 3}$ & $\mathbf{3 4 . 6 3}$ & $\mathbf{0 . 7 9}$ \\
\hline Variance & $\mathbf{1 6 . 9 6}$ & $\mathbf{1 9 . 1 0}$ & $\mathbf{3 1 . 7 4}$ \\
\hline Standard deviation & $\mathbf{4 . 1 2}$ & $\mathbf{4 . 3 7}$ & $\mathbf{2 1 . 6 0}$ \\
\hline
\end{tabular}

Markovina et al. [13] explored the validity and reliability of the (FCQ) across 9 European countries, including Portugal. Regarding the healthy motivations for Portugal, the reliability value was higher $(\alpha=0.914)$, when compared to the results obtained in this study.

\subsubsection{Emotional motivations}

Table 10 shows the internal reliability for variable EM (Emotional Motivations), and it was observed that the value of Cronbach's alpha with all items was 0.49 , which is considered unacceptable. When item 9 was removed the value increased to 0.66, and with the removal of items 2 and 9 the value increased to 0.70 , meaning an acceptable reliability. If items 4 and 8 were also removed, the value of alpha increased to 0.72 , maintaining internal reliability classified as acceptable. Therefore, it was decided that items 4 and 8 could be maintained. In fact, alpha tends to be higher when item-item correlation is stronger [19]. As it was previously shown in Table 4, items 2, 4 and 8 revealed a weak correlation with the other items. The value of Cronbach's alpha obtained in this study was a little lower, when compared to other studies $[3,13,45,46]$. 
Table 10. Internal reliability for Variable EM (Emotional Motivations).

\begin{tabular}{|lc|c|c|}
\hline \multirow{2}{*}{ Items } & \multicolumn{3}{c}{ Cronbach's alpha if item deleted } \\
\cline { 2 - 4 } & $\begin{array}{c}\text { Considering all } \\
\text { items }\end{array}$ & $\begin{array}{c}\text { Removing item } \\
\text { Removing } \\
\text { items 2 and 9 }\end{array}$ \\
\hline 1 - Stress & 0.37 & 0.58 & 0.63 \\
\hline 2 - Weight control & 0.51 & $\mathbf{0 . 7 0}$ & --- \\
\hline 3 - Stimulants & 0.45 & 0.66 & 0.70 \\
\hline $\mathbf{4}$ - Relaxing & 0.45 & 0.66 & $\mathbf{0 . 7 2}$ \\
\hline $\mathbf{5}$ - Good mood & 0.42 & 0.62 & 0.67 \\
\hline 6 - Feel alone & 0.36 & 0.57 & 0.61 \\
\hline 7 - Nothing to do & 0.41 & 0.62 & 0.66 \\
\hline $\mathbf{8}$ - Gain weight & 0.45 & 0.66 & $\mathbf{0 . 7 2}$ \\
\hline 9 - Emotional & $\mathbf{0 . 6 6}$ & -- & --- \\
\hline 10 - Depressed & 0.39 & 0.60 & 0.64 \\
\hline No of items considered & $\mathbf{1 0}$ & $\mathbf{9}$ & $\mathbf{8}$ \\
\hline Cronbach's alpha & $\mathbf{0 . 4 9}$ & $\mathbf{0 . 6 6}$ & $\mathbf{0 . 7 0}$ \\
\hline Mean & $\mathbf{3 0 . 5 6}$ & $\mathbf{2 7 . 3 6}$ & $\mathbf{2 4 . 1 4}$ \\
\hline Variance & $\mathbf{2 2 . 2 9}$ & $\mathbf{2 7 . 0 5}$ & $\mathbf{2 6 . 4 7}$ \\
\hline Standard deviation & $\mathbf{4 . 7 2}$ & $\mathbf{5 . 2 0}$ & $\mathbf{5 . 1 5}$ \\
\hline
\end{tabular}

\subsubsection{Economical and availability motivations}

Table 11 refers to the internal reliability for Variable EAM (Economical and Availability Motivations) and the results showed that with all items the value of alpha was equal to 0.62 , which is weak. However, when item 5 was deleted that value increased to 0.71 , meaning that internal reliability for Variable $\mathrm{C}$ was acceptable. Regarding the possible removal of item 1, it was observed that it would only cause a slight increase in the value of alpha $(\alpha=0.72)$. For that reason, item 1 was not eliminated. According to other studies, economical and availability motivations are usually considered as two separated variables $[13,45]$. Thus, when our findings were compared to both variables, economical and availability motivations from other studies, it was observed that the values of alpha obtained were slightly lower $(\alpha$ for price $=0.84, \alpha$ for availability and convenience $=0.89$ [13]; $\alpha$ for price $=0.82, \alpha$ availability and convenience $=0.81[45]$ ). 
Table 11. Internal reliability for Variable EAM (Economical and Availability Motivations).

\begin{tabular}{|c|c|c|}
\hline \multirow[b]{2}{*}{ Items } & \multicolumn{2}{|c|}{ Cronbach's alpha if item deleted } \\
\hline & $\begin{array}{c}\text { Considering all } \\
\text { items }\end{array}$ & $\begin{array}{c}\text { Removing item } \\
5\end{array}$ \\
\hline 1 - Quality/Price ratio & 0.63 & 0.72 \\
\hline 2 - Convenience & 0.58 & 0.68 \\
\hline 3 - Low price & 0.56 & 0.65 \\
\hline 4 - Easy to find & 0.56 & 0.65 \\
\hline 5 - Fresh to cook & 0.71 & --- \\
\hline 6 - Easy to prepare & 0.58 & 0.66 \\
\hline 7 - Sales & 0.56 & 0.65 \\
\hline 8 - Ready to eat & 0.62 & 0.69 \\
\hline $\mathbf{N}^{0}$ of items considered & 8 & 7 \\
\hline Cronbach's alpha & 0.64 & 0.71 \\
\hline Mean & 26.12 & 22.20 \\
\hline Variance & 14.85 & 15.13 \\
\hline Standard deviation & 3.85 & 3.89 \\
\hline
\end{tabular}

\subsubsection{Social and cultural motivations}

The internal reliability for Variable SCM (Social and Cultural Motivations) is shown in Table 12 and the results revealed that when all items were considered, the value of Cronbach's alpha was 0.54, which is considered inacceptable. Therefore, in order to obtain a higher value and consequently a better internal reliability, items 5,9 and 11 were deleted. In that case, alpha achieved a value equal to 0.66, which according to some authors could be considered acceptable [48-50]. Not surprisingly, the item-item correlations obtained for Variable SCM (Table 6) were in general weak. The value of Cronbach's alpha after the three items were deleted was similar to the one obtained in the study of Fotopoulos et al. [6] for the Variable Familiarity, which was equal to 0.61. 
Table 12. Internal reliability for Variable SCM (Social and Cultural Motivations).

\begin{tabular}{|c|c|c|c|c|}
\hline \multirow{2}{*}{ Items } & \multicolumn{4}{|c|}{ Cronbach's alpha if item deleted } \\
\hline & $\begin{array}{c}\text { Considering all } \\
\text { items } \\
\end{array}$ & $\begin{array}{c}\text { Removing item } \\
9 \\
\end{array}$ & $\begin{array}{c}\text { Removing } \\
\text { items } 5 \text { and } 9\end{array}$ & $\begin{array}{c}\text { Removing items } \\
5,9 \text { and } 11\end{array}$ \\
\hline 1 - Pleasure & 0.55 & 0.61 & 0.65 & 0.67 \\
\hline 2 - Company & 0.51 & 0.58 & 0.62 & 0.64 \\
\hline 3 - Food from infant time & 0.48 & 0.54 & 0.60 & 0.62 \\
\hline 4 - Follow trends & 0.48 & 0.55 & 0.60 & 0.62 \\
\hline 5 - Eat alone & 059 & 0.64 & --- & --- \\
\hline 6 - Food from the season & 0.50 & 0.57 & 0.62 & 0.63 \\
\hline 7 - Expectations & 0.46 & 0.54 & 0.60 & 0.63 \\
\hline 8 - Family tradition & 0.46 & 0.52 & 0.57 & 0.60 \\
\hline 9 - New foods & 0.60 & --- & --- & --- \\
\hline 10 - Food trends & 0.48 & 0.56 & 0.61 & 0.63 \\
\hline 11 - Unknown foods & 0.57 & 0.61 & 0.66 & --- \\
\hline $\mathbf{N}^{0}$ of items considered & 11 & 10 & 9 & 8 \\
\hline Cronbach's alpha & 0.54 & 0.60 & 0.64 & 0.66 \\
\hline Mean & 31.51 & 27.88 & 25.77 & 22.89 \\
\hline Variance & 19.01 & 19.03 & 18.51 & 16.15 \\
\hline Standard deviation & 4.36 & 4.36 & 4.30 & 4.02 \\
\hline
\end{tabular}

\subsubsection{Environmental and political motivations}

Table 13 presents the internal reliability for Variable EPM (Environmental and Political Motivations) and it was observed that the initial value of Cronbach's alpha was 0.63 , meaning a weak internal reliability. When item 3 was removed the alpha increased to 0.78 , which is acceptable. Moreover, the removal of any of the other items would not increase alpha, and thus, it was concluded that this variable has an acceptable internal reliability. The results obtained may be due to the fact that item 3 could be considered a negative question and, therefore, participants may had some doubts when they answered the questionnaire.

According to the study of Lindeman and Väänänen [17], environmental and political motivations were considered as two separate variables, and alpha values was higher for environmental motivations $(\alpha=0.91)$, but similar for political motivations $(\alpha=0.80)$, when compared to the value obtained in the present study. In a more recent study, ethical and environmental motivations were considered as one variable, and alpha value was equal to 0.97 [51], also higher than the value obtained $(\alpha=0.78)$. 
Table 13. Internal reliability for Variable EPM (Environmental and Political Motivations).

\begin{tabular}{|c|c|c|}
\hline \multirow[b]{2}{*}{ Items } & \multicolumn{2}{|c|}{ Cronbach's alpha if item deleted } \\
\hline & $\begin{array}{c}\text { Considering all } \\
\text { items }\end{array}$ & $\begin{array}{c}\text { Removing item } \\
3 \\
\end{array}$ \\
\hline 1 - Environmental friendly & 0.54 & 0.74 \\
\hline 2 - Avoid waist & 0.59 & 0.78 \\
\hline 3 - Country of origin & 0.78 & --- \\
\hline 4 - Food from my country & 0.61 & 0.78 \\
\hline 5 - Animal rights & 0.51 & 0.72 \\
\hline 6 - Human rights & 0.55 & 0.75 \\
\hline 7 - Restaurant waste policy & 0.56 & 0.76 \\
\hline 8 - Minimal packaging & 0.51 & 0.72 \\
\hline $\mathbf{N}^{\circ}$ of items considered & 8 & 7 \\
\hline Cronbach's alpha & 0.63 & 0.78 \\
\hline Mean & 27.38 & 24.39 \\
\hline Variance & 14.04 & 16.08 \\
\hline Standard deviation & 3.75 & 4.01 \\
\hline
\end{tabular}

\subsubsection{Marketing and commercial motivations}

Internal reliability for Variable MCM (Marketing and Commercial Motivations) is presented in Table 14 and the results showed a low value of Cronbach's alpha $(\alpha=0.32)$ when all items were considered. If items 1, 4, 6 and 7 were deleted alpha value increased to 0.78 , meaning an acceptable internal reliability. In fact, items 1, 4, 6 and 7 had already revealed a weak correlation with the other items, as it can be analysed in Table 8, being this one of the reasons to decrease the value of Cronbach's alpha [19]. In another study, the variable Visual Appealing of Foods initially contained 5 items and an alpha equal to 0.75 , similar to the value obtained in the present study [2]. 
Table 14. Internal reliability for Variable MCM (Marketing and Commercial Motivations).

\begin{tabular}{|c|c|c|c|c|c|}
\hline \multirow[b]{2}{*}{ Items } & \multirow[b]{2}{*}{$\begin{array}{c}\text { Considering } \\
\text { all items } \\
\end{array}$} & \multirow[b]{2}{*}{$\begin{array}{c}\text { Removing } \\
\text { item } 1\end{array}$} & \multicolumn{3}{|c|}{ Cronbach's alpha if item deleted } \\
\hline & & & $\begin{array}{c}\text { Removing } \\
\text { item } 1 \text { and } 4\end{array}$ & $\begin{array}{l}\text { Removing } \\
\text { item } 1,4,7 \\
\end{array}$ & $\begin{array}{c}\text { Removing } \\
\text { item } 1,4,6,7\end{array}$ \\
\hline 1 - Advertising campaigns & 0.50 & --- & --- & --- & --- \\
\hline 2 - Recognise TV commercials & 0.08 & 0.28 & 0.49 & 0.54 & 0.69 \\
\hline 3 - Appealing food & 0.20 & 0.39 & 0.58 & 0.63 & 0.76 \\
\hline 4 - Read labels & 0.44 & 0.65 & --- & --- & --- \\
\hline 5 - Desire for advertised foods & 0.16 & 0.33 & 0.51 & 0.55 & 0.67 \\
\hline 6 - Brands & 0.23 & 0.46 & 0.68 & 0.78 & --- \\
\hline 7 - Look for discounts & 0.25 & 0.47 & 0.70 & --- & --- \\
\hline $\mathrm{N}^{\mathbf{o}}$ of items considered & 7 & 6 & 5 & 4 & 3 \\
\hline Cronbach's alpha & 0.32 & 0.50 & 0.65 & 0.70 & 0.78 \\
\hline Mean & 21.17 & 18.13 & 14.49 & 11.19 & 8.30 \\
\hline Variance & 9.51 & 10.13 & 10.70 & 8.61 & 6.48 \\
\hline Standard deviation & 3.08 & 3.18 & 3.27 & 2.93 & 2.55 \\
\hline
\end{tabular}

\section{CONCLUSION}

This work allowed verifying satisfactory item analysis indicators for this questionnaire. This instrument offers the advantage of gathering in the same instrument different variables, that usually are separated. Furthermore, it adds some important items that were not considered in previous researches, such as, for example, the item 7 of Variable MCM. In general, were found statistically significant moderate and strong correlations between some items in all Variables, except for Variable SCM. For this variable, in most cases were not found strong correlations between the different items and the best correlation was only equal to 0.33 (correlation between items 4 and 3).

The initial values of Cronbach's alpha ranged from 0.32 for the Marketing and Commercial Motivations to 0.64 for the Economical and Availability Motivations. If some items were removed in each variable, alpha values increased and ranged from 0.66 to $0.78(\mathrm{SCM}=0.66 ; \mathrm{EM}=0.70 ; \mathrm{EAM}=$ $0.71 ; \mathrm{HM}=0.78 ; \mathrm{EPM}=0.78$, and $\mathrm{MCM}=0.78$ ), corresponding to an acceptable internal reliability.

Therefore, after initial validation, this questionnaire could be considered an adequate instrument to investigate several important motivations associated with food choices, and it could be applied in the ambit of the multinational project EATMOT, taking place in 18 countries. With that wider application more data will be available from a wider range of population that will allow comparing the eating motivations in the countries involved. 


\section{Acknowledgment}

This work was prepared in the ambit of the multinational project EATMOT from CI\&DETS Research Centre (IPV - Viseu, Portugal) with reference PROJ/CI\&DETS/CGD/0012.

\section{Annex A}

Table A.1 presents all the items that were included in the variables studied.

Table A.1. Items in the variables studied.

\begin{tabular}{|c|c|}
\hline Variable & Items \\
\hline \multirow{11}{*}{$\begin{array}{l}\text { HM: } \\
\text { Healthy } \\
\text { Motivations }\end{array}$} & 1. I am very concerned about the hygiene and safety of the food I eat \\
\hline & 2. It is important for me that my diet is low in fat \\
\hline & 3. Usually I follow a healthy and balanced diet \\
\hline & $\begin{array}{l}\text { 4. It is important for me that my daily diet contains a lot of vitamins and } \\
\text { minerals }\end{array}$ \\
\hline & 5. I do not avoid foods, even if they may raise my cholesterol \\
\hline & 6. I try to eat foods that do not contain additives \\
\hline & 7. I do not eat processed foods, because of their lower nutritional quality \\
\hline & 8. It is important for me to eat food that keeps me healthy \\
\hline & 9. I do not avoid foods, even if they may raise my blood glycaemia \\
\hline & 10. I avoid foods with genetically modified organisms \\
\hline & 11. It is important for me that my diet is low in sugar \\
\hline \multirow{10}{*}{$\begin{array}{l}\text { EM: } \\
\text { Emotional } \\
\text { Motivations }\end{array}$} & 1. Food helps me cope with stress \\
\hline & 2. I usually eat food that helps me control my weight \\
\hline & $\begin{array}{l}\text { 3. I often consume foods that keep me awake and alert (such as coffee, } \\
\text { coke, energy drinks) }\end{array}$ \\
\hline & 4. I often consume foods that helps me relax (such as some teas, red wine) \\
\hline & 5. Food makes me feel good \\
\hline & 6. When I feel lonely, I console myself by eating \\
\hline & 7. I eat more when I have nothing to do \\
\hline & 8. It is important for me to eat less than usual when I gain weight \\
\hline & 9. For me, food does not serve as an emotional consolation \\
\hline & 10. I have more cravings for sweets when I am depressed \\
\hline \multirow{2}{*}{$\begin{array}{l}\text { EPM: } \\
\text { Economical and } \\
\text { Availability }\end{array}$} & 1. I usually choose food that has a good quality/price ratio \\
\hline & $\begin{array}{l}\text { 2. It is important that the food I eat can be bought in shops close to where I } \\
\text { live or work }\end{array}$ \\
\hline
\end{tabular}




\begin{tabular}{|c|c|}
\hline \multirow[t]{6}{*}{ Motivations } & 3. The main reason for choosing a food is its low price \\
\hline & $\begin{array}{l}\text { 4. I choose the food I consume, because it is easy and convenient to } \\
\text { purchase }\end{array}$ \\
\hline & 5. I usually buy fresh food and cook it myself \\
\hline & 6. I usually buy food that is easy to prepare \\
\hline & 7. I usually buy food that it is on sale \\
\hline & 8. I prefer to buy food that is ready to eat or pre-cooked \\
\hline \multirow{11}{*}{$\begin{array}{l}\text { SCM: } \\
\text { Social and } \\
\text { Cultural } \\
\text { Motivations }\end{array}$} & 1. Meals are a time of fellowship and pleasure \\
\hline & 2. I eat more than usual when I have company \\
\hline & $\begin{array}{l}\text { 3. It is important to me that the food I eat is similar to the food I ate when I } \\
\text { was a child }\end{array}$ \\
\hline & $\begin{array}{l}\text { 4. I eat certain foods because other people (my colleagues, friends, family) } \\
\text { also eat it }\end{array}$ \\
\hline & 5. I prefer to eat alone \\
\hline & 6. I choose the foods I eat, because it fits the season \\
\hline & 7. I eat certain foods because I am expected to eat them \\
\hline & 8. My diet is determined by my family tradition \\
\hline & 9. I like to try new foods to which I am not accustomed \\
\hline & 10. I usually eat food that is trendy \\
\hline & $\begin{array}{l}\text { 11. I am not comfortable to eat food that I am not accustomed to or that I do } \\
\text { not know }\end{array}$ \\
\hline \multirow{8}{*}{$\begin{array}{l}\text { EPM: } \\
\text { Environmental and } \\
\text { Political } \\
\text { Motivations }\end{array}$} & $\begin{array}{l}\text { 1. It is important to me that the food I eat is prepared/packed in an } \\
\text { environmental friendly way }\end{array}$ \\
\hline & 2. When I cook I have in mind the quantities to avoid food waste \\
\hline & 3. When I consume or buy food, I do not care about the country of origin \\
\hline & 4. It is important to me that the food I eat comes from my own country \\
\hline & $\begin{array}{l}\text { 5. I prefer to eat food that has been produced in a way that animals' rights } \\
\text { have been respected }\end{array}$ \\
\hline & $\begin{array}{l}\text { 6. I choose foods that have been produced in countries where human rights } \\
\text { are not violated }\end{array}$ \\
\hline & $\begin{array}{l}\text { 7. I avoid going to restaurants that do not have a recovery policy of food } \\
\text { surplus }\end{array}$ \\
\hline & $\begin{array}{l}\text { 8. I prefer to buy foods that comply with policies of minimal usage of } \\
\text { packaging }\end{array}$ \\
\hline \multirow{5}{*}{$\begin{array}{l}\text { MCM: } \\
\text { Marketing and } \\
\text { Commercial } \\
\text { Motivations }\end{array}$} & 1. When I go shopping I am not influenced by marketing campaigns \\
\hline & $\begin{array}{l}\text { 2. I eat what I eat, because I recognize them from advertisements or have } \\
\text { seen it on TV }\end{array}$ \\
\hline & $\begin{array}{l}\text { 3. I usually buy food that spontaneously appeals to me (e.g. situated at eye } \\
\text { level, appealing colors, pleasant packaging) }\end{array}$ \\
\hline & $\begin{array}{l}\text { 4. When I go shopping I prefer to read food labels rather than to believe in } \\
\text { advertising campaigns }\end{array}$ \\
\hline & 5. Food advertising campaigns increases my desire to eat certain foods \\
\hline
\end{tabular}




\begin{tabular}{|ll|} 
6. & Brands are important to me when making food choices \\
\hline 7. & $\begin{array}{l}\text { I try to schedule my shopping for when I know there are promotions or } \\
\text { discounts }\end{array}$ \\
\hline
\end{tabular}

\section{References}

[1] European Food Information Council. Why do we eat what we eat: Food choice - a complex behaviour. Food Today 2004.

[2] Renner B, Sproesser G, Strohbach S, Schupp HT. Why we eat what we eat. The Eating Motivation Survey (TEMS). Appetite 2012;59:117-28. doi:10.1016/j.appet.2012.04.004.

[3] Pula K, Parks CD, Ross CF. Regulatory focus and food choice motives. Prevention orientation associated with mood, convenience, and familiarity. Appetite 2014;78:15-22. doi:10.1016/j.appet.2014.02.015.

[4] Steptoe A, Pollard TM, Wardle J. Development of a measure of the motives underlying the selection of food: the food choice questionnaire. Appetite 1995;25:267-84. doi:10.1006/appe.1995.0061.

[5] Machín L, Giménez A, Vidal L, Ares G. Influence of Context on Motives Underlying Food Choice. J Sens Stud 2014;29:313-24. doi:10.1111/joss.12107.

[6] Fotopoulos C, Krystallis A, Vassallo M, Pagiaslis A. Food Choice Questionnaire (FCQ) revisited. Suggestions for the development of an enhanced general food motivation model. Appetite 2009;52:199-208. doi:10.1016/j.appet.2008.09.014.

[7] Bublitz MG, Peracchio LA, Block LG. Why did I eat that? Perspectives on food decision making and dietary restraint. Journal of Consumer Psychology 2010;20:239-58. doi:10.1016/j.jcps.2010.06.008.

[8] Žeželj I, Milošević J, Stojanović Ž, Ognjanov G. The motivational and informational basis of attitudes toward foods with health claims. Appetite 2012;59:960-7. doi:10.1016/j.appet.2012.09.008.

[9] Forouzanfar MH, Alexander L, Anderson HR, Bachman VF, Biryukov S, Brauer M, et al. Global, regional, and national comparative risk assessment of 79 behavioural, environmental and occupational, and metabolic risks or clusters of risks in 188 countries, 1990-2013: a systematic analysis for the Global Burden of Disease Study 2013. Lancet 2015;386:2287-323. doi:10.1016/S0140-6736(15)00128-2.

[10] Thorndike AN, Riis J, Sonnenberg LM, Levy DE. Traffic-Light Labels and Choice Architecture: Promoting Healthy Food Choices. American Journal of Preventive Medicine 2014;46:143-9. doi:10.1016/j.amepre.2013.10.002.

[11] Barlow P, Reeves A, McKee M, Galea G, Stuckler D. Unhealthy diets, obesity and time discounting: a systematic literature review and network analysis. Obesity Reviews 2016;17:810-9. doi:10.1111/obr.12431.

[12] European Food Information Council. The Determinants of Food Choice. EUFICREVIEW 2006. 
[13] Markovina J, Stewart-Knox BJ, Rankin A, Gibney M, de Almeida MDV, Fischer A, et al. Food4Me study: Validity and reliability of Food Choice Questionnaire in 9 European countries. Food Quality and Preference 2015;45:26-32. doi:10.1016/j.foodqual.2015.05.002.

[14] Jackson B, Lynne Cooper M, Mintz L, Albino A. Motivations to eat: Scale development and validation. Journal of Research in Personality 2003;37:297-318. doi:10.1016/S00926566(02)00574-3.

[15] van Strien T, Frijters JER, Bergers GPA, Defares PB. The Dutch Eating Behavior Questionnaire (DEBQ) for assessment of restrained, emotional, and external eating behavior. Int J Eat Disord 1986;5:295-315. doi:10.1002/1098-108X(198602)5:2<295::AIDEAT2260050209>3.0.CO;2-T.

[16] ROININEN K, LÄHTEENMÄKI L, TUORILA H. Quantification of Consumer Attitudes to Health and Hedonic Characteristics of Foods. Appetite 1999;33:71-88. doi:10.1006/appe.1999.0232.

[17] Lindeman M, Väänänen M. Measurement of ethical food choice motives. Appetite 2000;34:559. doi:10.1006/appe.1999.0293.

[18] Aikman SN, Crites SL, Fabrigar LR. Beyond Affect and Cognition: Identification of the Informational Bases of Food Attitudes. Journal of Applied Social Psychology 2006;36:340-82. doi:10.1111/j.0021-9029.2006.00011.x.

[19] Hill MM, Hill A. Investigação por Questionário. 2a . Lisboa: Edições Sílabo; 2009.

[20] Likert R. A technique for the measurement of attitudes. Archives of Psychology 1932;22 140:55.

[21] Broen MPG, Moonen AJH, Kuijf ML, Dujardin K, Marsh L, Richard IH, et al. Factor analysis of the Hamilton Depression Rating Scale in Parkinson's disease. Parkinsonism \& Related Disorders 2015;21:142-6. doi:10.1016/j.parkreldis.2014.11.016.

[22] Hellstrom WJG, Feldman R, Rosen RC, Smith T, Kaufman G, Tursi J. Bother and Distress Associated with Peyronie's Disease: Validation of the Peyronie's Disease Questionnaire. The Journal of Urology 2013;190:627-34. doi:10.1016/j.juro.2013.01.090.

[23] Delaney M, McCarthy MB. Saints, sinners and non-believers: the moral space of food. A qualitative exploration of beliefs and perspectives on healthy eating of Irish adults aged 50-70. Appetite 2014;73:105-13. doi:10.1016/j.appet.2013.10.017.

[24] Guenther PM, Casavale KO, Reedy J, Kirkpatrick SI, Hiza HAB, Kuczynski KJ, et al. Update of the Healthy Eating Index: HEI-2010. Journal of the Academy of Nutrition and Dietetics 2013;113:569-80. doi:10.1016/j.jand.2012.12.016.

[25] Rao M, Afshin A, Singh G, Mozaffarian D. Do healthier foods and diet patterns cost more than less healthy options? A systematic review and meta-analysis. BMJ Open 2013;3:e004277. doi:10.1136/bmjopen-2013-004277.

[26] Wunderlich S, Gatto KA. Consumer Perception of Genetically Modified Organisms and Sources of Information. Adv Nutr 2015;6:842-51. doi:10.3945/an.115.008870.

[27] Macht M. How emotions affect eating: A five-way model. Appetite 2008;50:1-11. doi:10.1016/j.appet.2007.07.002.

[28] Immonen A-M. Essays on emotional influences in consumer food choice: Understanding emotional intricacies in consumers' price vs. ethicality trade-off decisions, and perceptions of genetically modified food products 2015 . 
[29] Kandiah J, Yake M, Jones J, Meyer M. Stress influences appetite and comfort food preferences in college women. Nutrition Research 2006;26:118-23. doi:10.1016/j.nutres.2005.11.010.

[30] Beydoun MA. The Interplay of Gender, Mood, and Stress Hormones in the Association between Emotional Eating and Dietary Behavior. J Nutr 2014;144:1139-41. doi:10.3945/jn.114.196717.

[31] Konttinen H, Silventoinen K, Sarlio-Lähteenkorva S, Männistö S, Haukkala A. Emotional eating and physical activity self-efficacy as pathways in the association between depressive symptoms and adiposity indicators. Am J Clin Nutr 2010;92:1031-9. doi:10.3945/ajen.2010.29732.

[32] Dallman MF, Pecoraro N, Akana SF, Fleur SE la, Gomez F, Houshyar H, et al. Chronic stress and obesity: A new view of "comfort food." PNAS 2003;100:11696-701. doi:10.1073/pnas.1934666100.

[33] Nevanperä NJ, Hopsu L, Kuosma E, Ukkola O, Uitti J, Laitinen JH. Occupational burnout, eating behavior, and weight among working women. Am J Clin Nutr 2012;95:934-43. doi:10.3945/ajen.111.014191.

[34] Higgs S, Thomas J. Social influences on eating. Current Opinion in Behavioral Sciences 2016;9:1-6. doi:10.1016/j.cobeha.2015.10.005.

[35] Bauer KW, Laska MN, Fulkerson JA, Neumark-Sztainer D. Longitudinal and Secular Trends in Parental Encouragement for Healthy Eating, Physical Activity, and Dieting Throughout the Adolescent Years. Journal of Adolescent Health 2011;49:306-11. doi:10.1016/j.jadohealth.2010.12.023.

[36] Lake AA, Rugg-Gunn AJ, Hyland RM, Wood CE, Mathers JC, Adamson AJ. Longitudinal dietary change from adolescence to adulthood: perceptions, attributions and evidence. Appetite 2004;42:255-63. doi:10.1016/j.appet.2003.11.008.

[37] Pedersen S, Grønhøj A, Thøgersen J. Following family or friends. Social norms in adolescent healthy eating. Appetite 2015;86:54-60. doi:10.1016/j.appet.2014.07.030.

[38] Onwezen MC. I did good, and we did bad: The impact of collective versus private emotions on pro-environmental food consumption. Food Research International 2015;76, Part 2:261-8. doi:10.1016/j.foodres.2015.03.032.

[39] Honkanen P, Verplanken B, Olsen SO. Ethical values and motives driving organic food choice. Journal of Consumer Behaviour 2006;5:420-30. doi:10.1002/cb.190.

[40] Auger P, Devinney TM. Do What Consumers Say Matter? The Misalignment of Preferences with Unconstrained Ethical Intentions. J Bus Ethics 2007;76:361-83. doi:10.1007/s10551-0069287-y.

[41] Dowd K, Burke KJ. The influence of ethical values and food choice motivations on intentions to purchase sustainably sourced foods. Appetite 2013;69:137-44. doi:10.1016/j.appet.2013.05.024.

[42] Carrington MJ, Neville BA, Whitwell GJ. Why Ethical Consumers Don't Walk Their Talk: Towards a Framework for Understanding the Gap Between the Ethical Purchase Intentions and Actual Buying Behaviour of Ethically Minded Consumers. J Bus Ethics 2010;97:139-58. doi:10.1007/s10551-010-0501-6.

[43] Johnston JL, Fanzo JC, Cogill B. Understanding Sustainable Diets: A Descriptive Analysis of the Determinants and Processes That Influence Diets and Their Impact on Health, Food 
Security, and Environmental Sustainability. Adv Nutr 2014;5:418-29. doi:10.3945/an.113.005553.

[44] Boyland EJ, Halford JCG. Television advertising and branding. Effects on eating behaviour and food preferences in children. Appetite 2013;62:236-41. doi:10.1016/j.appet.2012.01.032.

[45] Eertmans A, Victoir A, Notelaers G, Vansant G, Van den Bergh O. The Food Choice Questionnaire: Factorial invariant over western urban populations? Food Quality and Preference 2006;17:344-52. doi:10.1016/j.foodqual.2005.03.016.

[46] Honkanen P, Frewer L. Russian consumers' motives for food choice. Appetite 2009;52:363-71. doi:10.1016/j.appet.2008.11.009.

[47] Milošević J, Žeželj I, Gorton M, Barjolle D. Understanding the motives for food choice in Western Balkan Countries. Appetite 2012;58:205-14. doi:10.1016/j.appet.2011.09.012.

[48] Davis FB. Educational Measurements and Their Interpretation. Wadsworth Publishing Company; 1964.

[49] Hair J, Black W, Babin B, Anderson R. Multivariate Data Analysis - a global perspective. 7th ed. Prentice Hall: Pearson; 2009.

[50] Maroco J, Garcia-Marques T. Qual a fiabilidade do alfa de Cronbach? Questões antigas e soluções modernas? Laboratório de psicologia 2006:65-90.

[51] Sautron V, Péneau S, Camilleri GM, Muller L, Ruffieux B, Hercberg S, et al. Validity of a questionnaire measuring motives for choosing foods including sustainable concerns. Appetite 2015;87:90-7. doi:10.1016/j.appet.2014.12.205. 